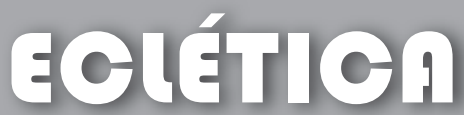 química
}

\section{SPECTROPHOTOMETRIC DETERMINATION OF NEVIRAPINE USING TETRATHIOCYANATOCOBALT(II) ION AS A REAGENT}

\author{
T. V. Sreevidya \& B. Narayana* \\ Department of Post-Graduate Studies and Research in Chemistry, \\ Mangalore University, Mangalagangotri-574 199, \\ Karnataka, INDIA. \\ *E-mail: nbadiadka@yahoo.co.uk
}

\begin{abstract}
A simple and rapid spectrophotometric method for the determination of nevirapine is described. The method is based on the reaction of nevirapine with tetrathiocyanatocobalt(II) ion in buffer of $\mathrm{pH} 4$ to form the corresponding complex. Beer's law is obeyed in the range of $0.2-2.0 \mu \mathrm{g} \mathrm{mL} \mathrm{m}^{-1}$ for nevirapine. The optical parameters such as molar absorptivity, Sandell's sensitivity, detection limit and quantitation limit were found to be $1.16 \times 10^{4} \mathrm{Lmol}^{-1} \mathrm{~cm}^{-1}, 2.09$ $\times 10^{-3} \mu \mathrm{g} \mathrm{cm}^{-2}, 0.073 \mu \mathrm{g} \mathrm{mL} \mathrm{m}^{-1}$ and $0.222 \mu \mathrm{g} \mathrm{mL^{-1 }}$ respectively. The optimum reaction conditions and other analytical parameters were evaluated. The statistical evaluation of the method was examined by determining intra-day and inter-day precision. The proposed method has been successfully applied for the determination of nevirapine in pharmaceutical formulations.
\end{abstract}

Keywords: Spectrophotometry, Nevirapine, Tetrathiocyanatocobalt(II) ion.

\section{Introduction}

Nevirapine (NVP) chemically 11-cyclopropyl-4-methyl-5,11-dihydro-6Hdipyrido[3,2-b:2',3'-e][1,4]diazepin-6-one, is a non-nucleoside reverse transcriptase inhibitor (NNRTI) class of antiretrovirals used for the treatment of HIV-1 infections and AIDS [1-3]. Nevirapine is structurally a member of the dipyridodiazepinone chemical class of compounds. It is used in resource poor areas and it is available as a part in generic drug combinations. It is an inducer of cytochrome P450 isoenzymes CYP3A4 and CYP2B6 $[4,5]$. Nevirapine in triple combination therapy has been shown to suppress viral load effectively when used as initial antiretroviral therapy $[6,7]$. It is a potent and selective non-competitive inhibitor of reverse transcriptase, an important therapeutic target for treatment of
HIV-1. The introduction of highly effective combination regimens of antiretroviral drugs has led in recent years to substantial improvements in morbidity and mortality. Combination of antiretroviral therapy is the most effective approach to managing HIV infection [8-10]. Although early clinical trials with nevirapine found that its use as a monotherapy resulted in the rapid onset of resistance and hypersensitivity reactions $[11,12]$, it is now evident that nevirapine is effective when used as part of highly active antiretroviral therapy [13] (HAART) and may offer an alternative to the inclusion of protease inhibitors (which have been associated with toxicity during long term use) in such treatment [14]. Furthermore, compared with the protease inhibitors, nevirapine offers more convenient administration regimens (once daily dosing is possible, and there are no food restric- 
tions), which has meant that it is a particularly successful anti-HIV treatment for young children.

Several analytical techniques have been reported for the determination of nevirapine [1525]. The method in the United States Pharmacopoeia (USP)—-monograph for determining nevirapine and its related compounds, A and B-uses a reversed-phase separation with UV detection [26]. The method calls for a $4.6 \times 150 \mathrm{~mm}$ column paThe method calls for a $4.6 \times 150 \mathrm{~mm}$ column pa-
cked with L 60 (spherical, porous silica gel, $10 \varnothing \mathrm{m}$ cked with L 60 (spherical, porous silica gel, $10 \varnothing \mathrm{m}$
or less in diameter, the surface of which has been covalently modified with alkyl amide groups and endcapped). Due to the strong retention of impurity $C$, the separation requires about 30 minutes. In the present work we discuss a rapid spectrophotometric method for the routine determination of nevirapine using tetrathiocyanatocobalt(II) ion as a reagent in pure and dosage forms.

\section{Experimental}

Apparatus

A Shimadzu UV-2550 UV-VIS Spectrophotometer with $1 \mathrm{~cm}$ matched quartz cells was used for absorbance measurements.

\section{Reagents and Solutions}

All chemicals used were of analytical reagent grade. NVP drug was obtained as gift sample from SeQuent Scientific Ltd, Mangalore. Commercial tablets containing $200 \mathrm{mg}$ were used for the study of dosage forms.

A $1000 \mu \mathrm{g} \mathrm{mL}^{-1}$ standard drug solution was prepared by dissolving $0.1 \mathrm{~g}$ of NVP in alcohol diluting to the mark in a $100 \mathrm{~mL}$ standard flask. For the calibration samples, a working solution was prepared by appropriate dilution of the stock concentration in ethanol. Buffer of $p \mathrm{H} 4$ was prepared by transferring one buffer tablet of $p \mathrm{H} 4$ in 100 $\mathrm{mL}$. Tetrathiocyanatocobalt(II) ion (TTC) was prepared by mixing $4 \mathrm{~g}$ cobalt(II) chloride with 20g KSCN and made up to $100 \mathrm{~mL}$ with distilled water in a standard flask.
Procedure

Determination of nevirapine using tetrathiocyanatocobalt(II) ion

Different aliquots containing $0.2-2.0 \mu \mathrm{g}$ $\mathrm{mL}^{-1}$ of NVP were transferred into a series of 10 $\mathrm{mL}$ standard flasks using a micro burette. To this 4 $\mathrm{mL}$ of tetrathiocyanatocobalt(II) ion solution was added followed by $2 \mathrm{~mL}$ of $p \mathrm{H} 4$ buffer solution. The contents were shaken well and set aside for 10 minutes and diluted up to the mark with distiled water and mixed well. The absorbance of each $5 \mathrm{~nm}$ against the corresponding reagent blank.

\section{Assay of formulations}

To determine the content of nevirapine in conventional tablets (label claim: $200 \mathrm{mg} /$ tablet), the tablets were powdered and powder equivalent to $100 \mathrm{mg}$ of nevirapine was weighed. The drug from the powder was extracted with ethanol. To ensure complete extraction of the drug, it was sonicated for $30 \mathrm{~min}$ and volume was made up to $100 \mathrm{~mL}$. The analysis was repeated in triplicate. The possibility of excipients interference in the analysis was studied.

\section{Results and Discussion}

The method involves the reaction of NVP with TTC in $p \mathrm{H} 4$ to form a complex [Scheme 1], which has an absorption maximum at $624.5 \mathrm{~nm}$ [Fig. 1]

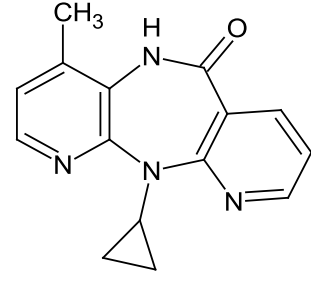

$\left[\mathrm{Co}(\mathrm{NCS})_{4}\right]^{2-}$ 


\section{Analytical Data}

The adherence of Beer's law was studied by measuring the absorbance values of the solutions varying analyte concentration [Fig. 2]. A linear relation was found between absorbance at $\lambda$ and concentration ranges given in table 1. Regression analysis of Beer's law data using the method of least squares were made to evaluate the slope (a), intercept (b) and correlation coefficient (R), for each system of NVP and are also presented in table 1 . Sensitivity parameters such as molar absorptivity, Sandell's sensitivity, detection limit and quantification limit are also compiled in table 1 . The limit of detection and quantitation are calculated according to ICH guidelines.

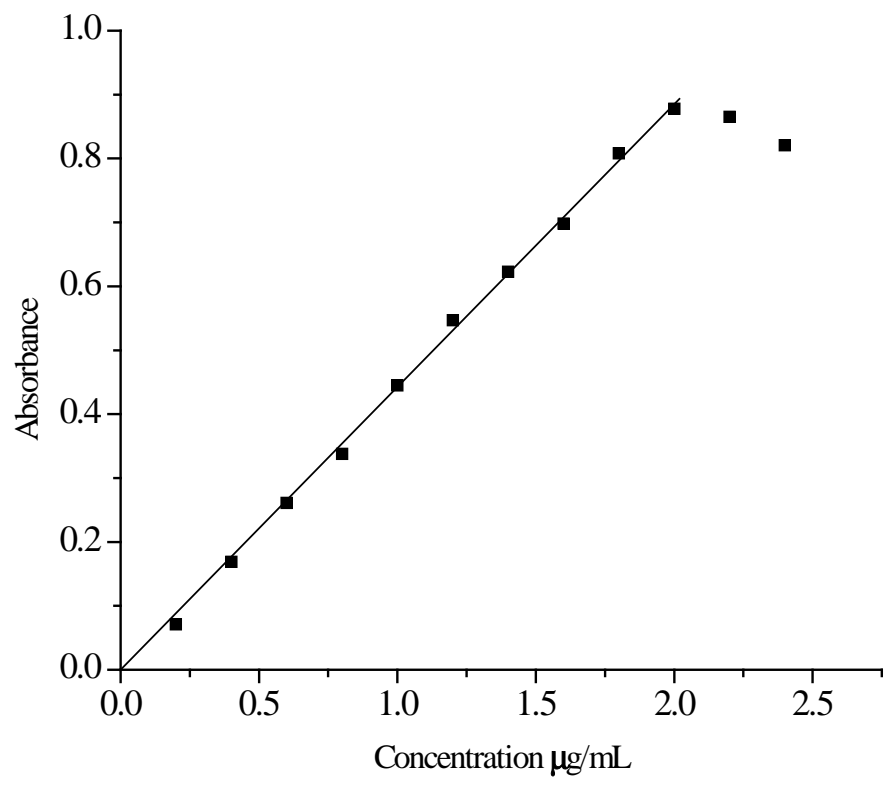

Figure 2. Adherence of Beer's law
Table 1. Analytical parameters

\begin{tabular}{ll}
\hline Parameters & Nevirapine (NVP) \\
\hline$\lambda_{\text {max }}(\mathrm{nm})$ & 624.5 \\
Beer's law limits $\left(\mu \mathrm{g} \mathrm{mL}^{-1}\right)$ & $0.2-2.0$ \\
Molar Absorptivity $\left({\left.\mathrm{L} \mathrm{mol}-1 \mathrm{~cm}^{-1}\right)}^{-1}\right)$ & $1.16 \times 10^{4}$ \\
Sandell's sensitivity $\left(\mu \mathrm{g} \mathrm{cm}^{-2}\right)$ & $2.09 \times 10^{-3}$ \\
Limit of detection** $\left(\mu \mathrm{g} \mathrm{m}^{-1}\right)$ & 0.073 \\
Limit of quantification** $\left(\mu \mathrm{g} \mathrm{mL}^{-1}\right)$ & 0.222 \\
Regression equation* & $\mathrm{y}=\mathrm{ax}+\mathrm{b}$ \\
Slope (a) & 0.4508 \\
Intercept (b) & -0.0135 \\
Correlation coefficient $(\mathrm{R})$ & 0.9993
\end{tabular}

* $\mathrm{y}$ is the absorbance and $\mathrm{x}$ is the concentration in $\mu \mathrm{g} \mathrm{mL}^{-1}$

** Calculated using ICH - Guidelines

Stability of the Complex

An aliquot containing $2 \mu \mathrm{g} \mathrm{mL}^{-1}(2 \mathrm{~mL})$ of NVP was pipetted from the stock solution of NVP $\left(10 \mu \mathrm{g} \mathrm{mL}^{-1}\right)$ into a $10 \mathrm{~mL}$ calibrated flask. To this $2 \mathrm{~mL}$ buffer of $p \mathrm{H} 4$ and $4 \mathrm{~mL}$ of TTC were added and mixed well for 10 minutes and made up to 10 $\mathrm{mL}$. The absorbance was measured at $624.5 \mathrm{~nm}$ at $\mathrm{mL}$. The absorbance was measured at $624.5 \mathrm{~nm}$ at bances were obtained which indicated the stability of the complex and was found to be stable over two days. 


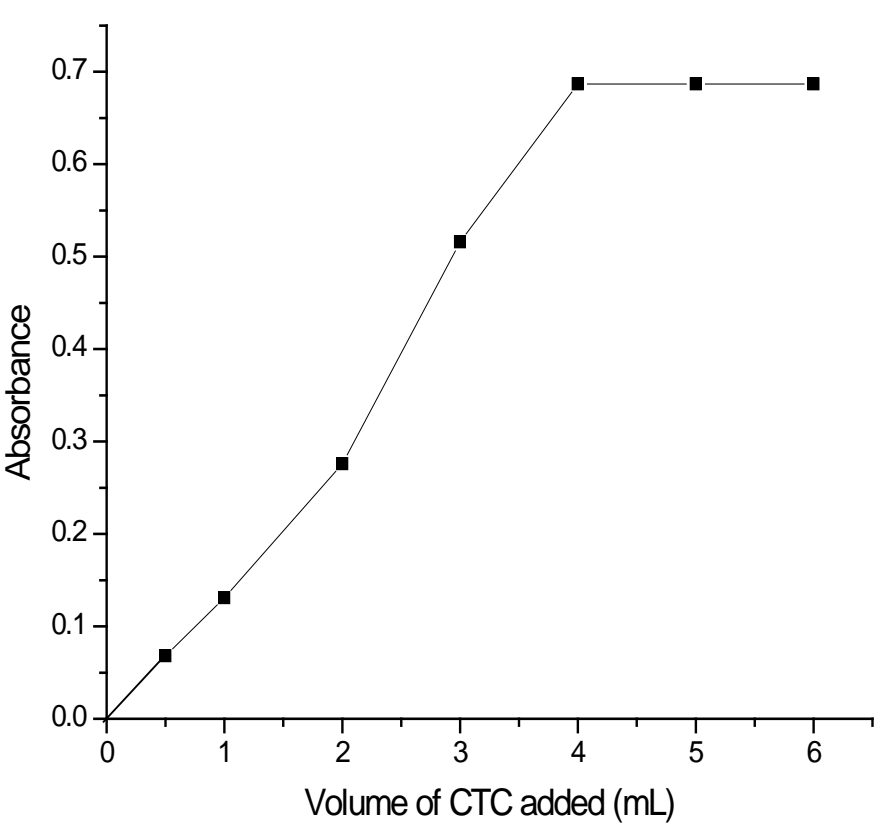

Figure 3. Optimum concentration of reagent TTC

Optimum Volume of Reagent

An aliquot containing $2 \mu \mathrm{g} \mathrm{mL}^{-1}(2 \mathrm{~mL})$ of NVP was pipetted out from the stock solution of NVP $\left(10 \mu \mathrm{g} \mathrm{mL}^{-1}\right)$ into a $10 \mathrm{~mL}$ calibrated flask along with $2 \mathrm{~mL}$ of buffer solution of $p \mathrm{H} 4$. Then it was mixed with TTC in the order of $0.5 \mathrm{~mL}, 1$ $\mathrm{mL}, 2 \mathrm{~mL}, 3 \mathrm{~mL}, 4 \mathrm{~mL}, 5 \mathrm{~mL}$ and $6 \mathrm{~mL}$. The complexes were made up to $10 \mathrm{~mL}$ and absorbance was measured at $624.5 \mathrm{~nm}$. It was found that the volume between 4 and $6 \mathrm{~mL}$ is optimum volume of the reagent to get the maximum absorbance and $4 \mathrm{~mL}$ was chosen for the experiment [Fig. 4].

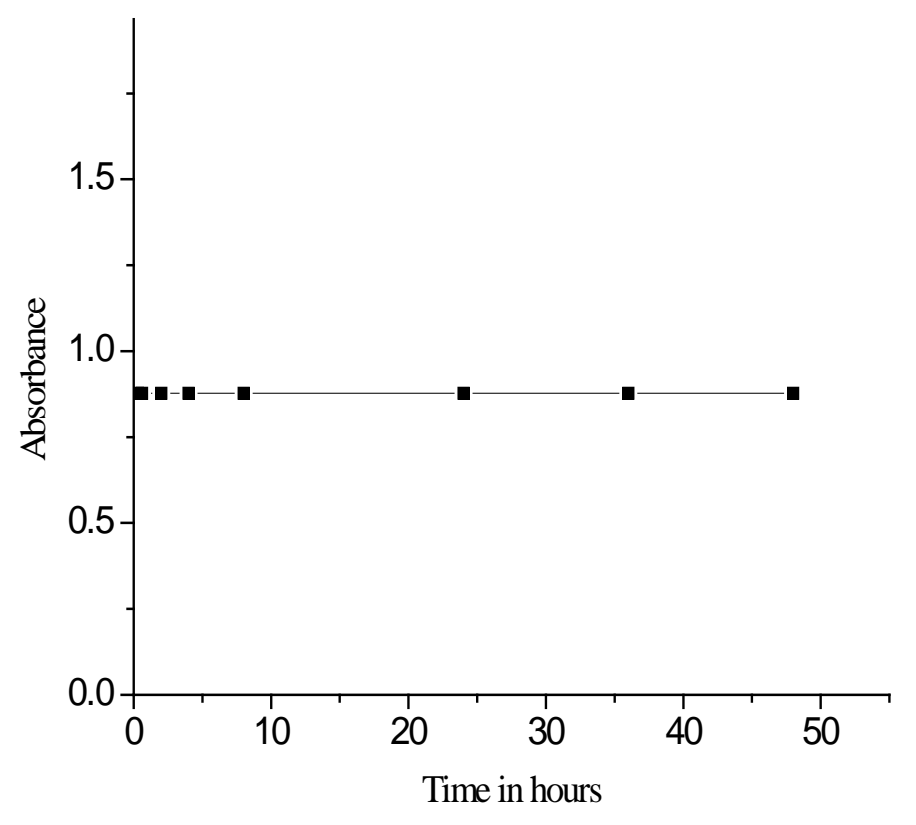

Figure 4. Stability of NVP-TTC complex

Stability Constant of the Complex (TurnerAnderson Method)

Equimolar solutions of NVP and TTC are mixed in complimentary proportions such that the final volume is $10 \mathrm{~mL}$ and the solutions are made up to the mark in $25 \mathrm{~mL}$ standard flasks using buffer of $p \mathrm{H} \mathrm{4.0.} \mathrm{The} \mathrm{absorbances} \mathrm{of} \mathrm{these} \mathrm{are} \mathrm{mea-}$ sured at $624.5 \mathrm{~nm}$ against the reagent blank. The experiment is repeated by changing the concentration of NVP and TTC. The graphs are plotted with absorbance versus mole ratio of NVP-TTC w complex [Fig. 5]. The stability constant of the complex is calculat to be $2.7 \times 10^{4}$. 
Table 2. Evaluation of accuracy and precision

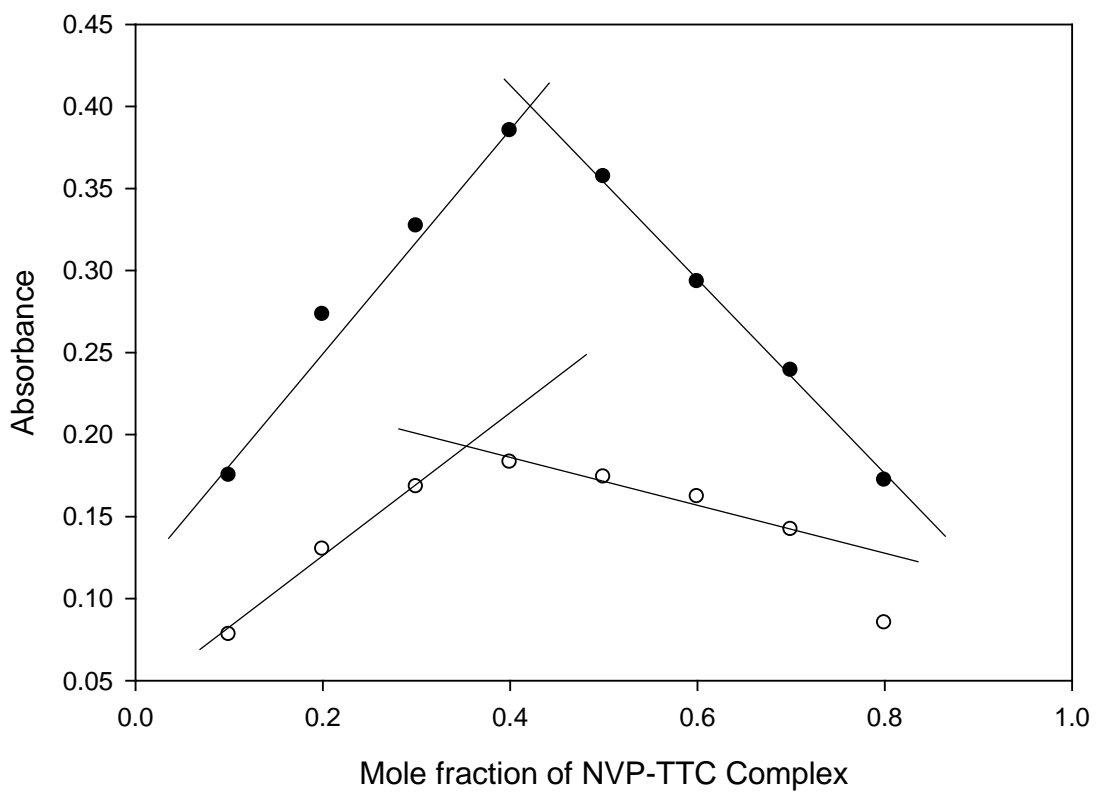

Figure 5. Continuous variation graph for TTC-NVP Complex

\section{Method Validation}

The proposed method is applied to the assay of NVP in three commercially available dietay supplements. An aliquot containing $1.2 \mu \mathrm{g} \mathrm{mL} \mathrm{L}^{-1}$ drug solution is taken and assayed according to proposed methe The content of the toble is foris ay a fired y a thorough analysis of each spiked sample and the results are compiled in table 3 .The accuracy and reliability of the proposed method are further established by performing recovery studies. The relative error and relative standard deviation indicate the high accuracy and precision for the method and are compiled in table 2 . For a better picture of reproducibility on a day- to-day basis, picture reprodiction on a day- to-day basis, arand dur and peach day for five days with all solutions being prepared afresh each day. The day-to-day relative standard deviation values represent the best appraisal of the method in routine use.

\begin{tabular}{ccccc}
\hline $\begin{array}{c}\text { Amount taken } \\
\left(\mu \mathrm{gL}^{-1}\right)\end{array}$ & $\begin{array}{c}\text { Amount found* } \\
\left(\mu \mathrm{gL}^{-1}\right)\end{array}$ & $\begin{array}{c}\mathrm{SD} \\
\left(\mu \mathrm{g} \mathrm{mL}^{-1}\right)\end{array}$ & $\begin{array}{c}\mathrm{RE} \\
(\%)\end{array}$ & $\begin{array}{c}\text { RSD } \\
(\%)\end{array}$ \\
\hline 0.4 & 0.401 & 0.002 & 0.15 & 0.379 \\
0.6 & 0.602 & 0.002 & 0.23 & 0.417 \\
0.8 & 0.801 & 0.002 & 0.05 & 0.287 \\
1.0 & 1.003 & 0.006 & 0.34 & 0.604 \\
1.2 & 1.202 & 0.008 & 0.17 & 0.696 \\
1.4 & 1.404 & 0.009 & 0.29 & 0.637 \\
1.6 & 1.604 & 0.006 & 0.25 & 0.341 \\
1.8 & 1.802 & 0.013 & 0.11 & 0.724 \\
\hline
\end{tabular}

* Average of five determinations

SD- Standard deviation, RE- Relative error, RSD-Relative standard deviation

\section{Interference Study}

In pharmaceutical analysis, it is important to test the selectivity towards the excipients and fillers added to the pharmaceutical preparations. Several species which can occur in the real samples togethe with drug were investigated. The level of interference was considered acceptable. Commonly encountered excipients such as talc, starch, glucose etc did not interfere in the determination.

\section{Applications}

The proposed methods were applied to the determination of NVP in three commercial dietary supplements (tablets). An aliquot containing $1.2 \mu \mathrm{g} \mathrm{mL}^{-1} \mathrm{drug}$ solution was taken and assayed according to the proposed methods. The content of the tablet formulation was calculated by applying suitable dilution factor. The accuracy of the proposed method was checked by a thorough analysis of each spiked sample and the results are compiled in table 3 . The accuracy and reliability of the methods were further ascertained by recovery studies.

Table 3. Results of assay of formulations by the proposed method

\begin{tabular}{ccc}
\hline Brand name of tablet & Labeled amount (mg) & Found $^{*} \pm$ SD (mg) \\
\hline Nevimune $^{\mathrm{a}}$ & 200 & $200.25 \pm 0.008$ \\
Nevipan $^{\mathrm{b}}$ & 200 & $200.59 \pm 0.045$ \\
Neviretro $^{\mathrm{c}}$ & 200 & $198.25 \pm 0.016$ \\
\hline
\end{tabular}

*Mean value of three determinations;

'Cipla Pharmaceuticals; ' ${ }^{\circ}$ Ranbaxy Pharmaceuticals; ' $A l k e m$ Laboratories. 


\section{Conclusions}

Simple spectrophotometric method for the determination of NVP have been developed and validated according to ICH guidelines. The method is simple and easy to perform compared to other existing methods and do not entail any rigorous experimental variables which affect the reliability of the results. The ingredients usually present in the pharmaceutical formulations of these drugs seldom interfere in the proposed methods. The proposed method is simple, accurate and easy to perform and can be used for the routine determination of NVP in bulk and in dosage forms.

\section{References}

[1] S. Staszewski, J. Morales-Ramirez, K. T. Tashima, A. Rachlis, D. Skiest, J. Stanford, R. Stryker, P. Johnson, D. F. Labriola, D. Farina, D. J. Manion, N. M. Ruiz, N. Engl. J. Med. 341 (1999) 1865.

[2] J. S. G. Montaner, P. Reiss, D. Cooper, S. Vella, M. Harris, B. Conway, M. A. Wainberg, D. Smith, P. Robinson, D. Hall, M. Myers, J. M. A. Lange, JAMA, 279 (1998) 930. [3] D. Podzamczer, E. Ferrer, E. Consiglio, J. M. Gatell, P. Perez, J. L. Perez, E. Luna, A. Gonzalez, E. Pedrol, L. Lozano, I. Ocana, J. M. Llibre, A. Casiro, M. Aranda, P. Barrufet, J. Martinez-Lacasa, J. M. Miro, X. Badia, A. Casado, S. Lupo, P. Cahn, M. Manos, J. Estela, Antivir Ther. 7 (2002) 81.

[4] L. I. Malaty, J. J. Kupper, Drug Sar. 20 (1999)147.

[5] D. Back, S. Gibbons, S. Khoo, J. Acquir. Immune Defic. Syndr. 34 (2003) S8-14.

[6] R. Panchagnula, S. Agrawal, Y. Ashokraj, M.V.S. Varma, K. Sateesh, V. Bhardwaj, S. Bedi, I. Gulati, J. Parmar, C. Kaul, B. Blomberg, B. Fourie, G. Roscigno, R. Wire, R. Laing , P. Evans, T. Moore, Methods Find. Exp. Clin. Pharmacol. 26 (2004) 703.

[7] D. Rey, M. Partisani, H. -K. Georgette, V. Krantz, M. Priester, C. Christine, B. -H. Claudine, E. de Mautort, L. Decroix, J.-M. Lang, J. Acquir. Immune Defic. Syndr. 37 (2004) 1454.

[8] C. C. J. Carpenter, M. A. Fischl, S. M. Hammer, M. S. Hirsch, D. M. Jacobsen, D. A. Katzenstein, J. S. G. Montaner, D. D. Richman, M. S. Saag, R. T. Schooley, M. A. Thompson, S. Vella, P. G. Yeni, P. A. Volberding, J. Am. Med. Assoc. 77 (1997) 1962.

[9] R. M. Gulick, J. M. Mellors, D. Havlir, J. J. Eron, C. Gonzalez, D. McMahon, D. D. Richman, F. T. Valentine, L. Jonas, A. Meibohm, E. A. Emini, J. A. Chodekewitz, N. Engl. J. Med. 337 (1997) 734.
[10] W. Cavert, D. W. Notermans, K. Staskus, W. W.Stephen, Z. Mary, G. Kristin, H. Keith, Z. -Q. Zhang, R. Mills, H. McDade, J. Goudsmit, S. A. Danner \& T. H. Ashley, Science 276 (1997) 960.

[11] A. Carr, D. A. Cooper, Adv. Exp. Med. Biol. 394 (1996) 299.

[12] S. M. Hammer, J. Infect. Dis. 192 (2005) 1.

[13] M. Hartmann, S. Witte, J. Brust, D. Schuster, F. Mosthaf, M. Procaccianti, J. A. Rump, H. Klinker, D. Petzoldt, Int. J. STD. AIDS 16 (2005) 404.

[14] P. Barreiro, V. Soriano, F. Blanco, C. Casimiro, J. J. de la Cruz, J. Gonzalez-Lahoz, AIDS 14 (2000) 807.

[15] N. L. Rezk, R. R. Tidwell, A. D. M. Kashuba, J. Chromatogr. B (2004) 805, 241.

[16] C. F. Silverthorn, T. L. Parsons, Biomed. Chromatogr. 20 (2006) 23.

[17] G. Ramachandran, A. K. Hemanthkumar, V. Kumaraswami, S. Swaminathan, J. Chromatogr. B 843 (2006) 339.

[18] B. H. Chi, A. Lee, E. P. Acosta, L. E. Westerman, M. Sinkala, J. S. A. Stringer, HIV Clin. Trials 7 (2006) 263.

[19] R. ter Heine, H. Rosing, E. C. M. van Gorp, J. W. Mulder, W. A. van der Steeg, J. H. Beijnen, A. D. R. Huitema, J. Chromatogr. B 867 (2008) 205.

[20] R. Sekar, S. Azhaguvel, Chromatographia 67 (2008) 389.

[21] S. Notari, C. Mancone, T. Alonzi, M. Tripodi, P. Narciso, P. Ascenzi, J. Chromatogr. B 863 (2008) 249.

[22] G. Ramachandran, A. K. Hemanthkumar, V. Kumaraswami, S. Swaminathan, J. Chromatogr. B 843 (2006) 339.

[23] G. R. Da Silva, G. P. Lages, G.A. Pianetti, E.D.A. Nunan, C. D. V. Soares, L. M. M. De Campos, Quimica Nova 29 (2006) 1159.

[24] C. F. Silverthorn, T. L. Parsons, Biomed. Chromatogr. 20 (2006) 23.

[25] P. Lemmer, S. Schneider, M. Schuman, C. Omes, V. Arendt, J.-C. Tayari, L. Fundira, R. Wennig, Therapeutic Drug Monitoring 27 (2005) 521.

[26] U. S. Pharmacopeia 29 NF 24 (2006) 29 15-19-1520. 